\title{
Nonkardiyak Göğüs Ağrısı Şikayeti Olan Bireylerde D Tipi Kişilik, Psikiyatrik Belirtiler ve Ağrı Şiddeti Arasındaki İlişki
}

\author{
İbrahim YAĞCI ${ }^{1}$, Yasin TAŞDELEN $\mathbb{0}^{2}$, Fatih AYDIN $\mathbb{0}^{3}$
}

\section{ÖZ}

Amaç: Göğüs ağrısı şikâyeti toplumda yaygın olarak görülür. Göğüs ağrısının etiyolojisinde en sık olarak kardiyak nedenler olmakla psikiyatrik bozukluklarda sık görülen nedenler arasındadır. Bu şikayet kalp rahatsızlı̆ğ ile ilgili sürekli endişeye ve sağlık hizmetlerinin tekrarlayan kullanımına neden olması açısından önemli bir sağlık sorunudur. Nonkardiyak göğüs ağrısı (NKGA) şikâyeti olan hastalarda psikiyatrik belirtiler araştırılmış olmakla birlikte D Tipi kişilik araştırılmamıştır. $\mathrm{Bu}$ nedenle göğüs ağrısı şikâyeti olan bireylerde psikiyatrik belirtiler ile bu belirtilerle hissedilen ağrı şiddeti arasındaki ilişkiyi incelemek için bu çalışma planlanmıştır.

Gereç ve Yöntemler: NKGA tanısı konulan 100 kişi ile hasta grubu, sağlıklı 100 kişi ile kontrol grubu oluşturuldu. Olgulara Sosyodemografik Veri Formu, Beck Depresyon ölçeği, Çocukluk Çağı Travmaları Ölçeği, D Tipi Kişilik Ölçeği, bedensel duyumları abartma ölçeği, Toronto Aleksitimi ölçeği uygulandı.

Bulgular: Sosyodemografik verilere bakıldığında hasta grubu ile kontrol grubu arasında yaş, cinsiyet, medeni hal, çalışma durumu ve eğitim düzeyleri bakımından anlamlı fark bulunmadı. Hasta grubundaki bireylerde kontrol grubuna göre depresyon, aleksitimi, bedensel duyumları abartma, D Tipi Kişilik ve çocukluk çağı travmatik yaşantılar ölçek puanlarının anlamlı olarak daha yüksek olduğu ayrıca D Tipi kişilik özelliklerinin ağrı şiddeti ile ilişkili olduğu bulunmuştur.

Sonuç: NKGA şikâyeti olan hastalarda psikiyatrik belirtiler sık olarak görülmektedir. Psikiyatrik bozuklukların tespit edilmesi ve tedavi edilmeleri ile birlikte tekrarlayan hastane başvurularının azaltılabileceğini düşünüyoruz.

Anahtar Kelimeler: Nonkardiyak göğüs ağrısı; depresyon; aleksitimi; tip D kişilik

\section{The Relationship between Type D Personality, Psychiatric Symptoms and Pain Severity in Individuals with Noncardiac Chest Pain Complaints}

\begin{abstract}
Aim: Complaints of chest pain are common in society. Cardiac causes are the most common etiology of chest pain, and they are among the common causes of psychiatric disorders. This complaint is an important health problem in that it causes constant concern about heart disease and repetitive use of health services. Psychiatric symptoms have been investigated in patients complaining of noncardiac chest pain (NCCP), however Type D personality has not been investigated. Therefore, this study was planned to examine the association between psychiatric symptoms and the severity of pain felt with these symptoms in people who complain of chest pain.

Material and Methods: The patient group with 100 individuals diagnosed with NCCP, and the control group with 100 healthy individuals were formed. Socio-demographic Data Form, Beck Depression Inventory, Childhood Trauma Questionnaire, Type D Personality Scale, Somatosensory Amplification Scale, and Toronto Alexithymia scale were applied to the subjects.

Results: Considering the sociodemographic data, no significant difference was found between the patient group and the control group in terms of age, gender, marital status, employment status and education level. It was found that depression, alexithymia, somatosensory amplification, Type D Personality and childhood traumatic experiences scale scores were significantly higher in individuals in the patient group compared to the control group, and that Type D personality traits were associated with pain severity.
\end{abstract}

1 Kars Harakani Devlet Hastanesi, Psikiyatri Kliniği, Kars, Türkiye

2 Aydın Devlet Hastanesi, Psikiyatri Kliniği Aydın, Türkiye

3 Eskişehir Şehir Hastanesi Kardiyoloji kliniği, Eskişehir, Türkiye 
Conclusion: Psychiatric symptoms are common in patients with NCCP. We are of the opinion that detection and treatment of psychiatric disorders might reduce recurrent hospital admissions.

Keywords: Noncardiac chest pain; depression; alexithymia; type D personality.

\section{GİRIŞ}

Göğüs ağrısı şikâyeti toplumda yaygın olarak görülür. Göğüs ağrısının etiyolojisinde kardiyak nedenler olabilmekle birlikte depresyon, anksiyete, panik atak gibi psikiyatrik bozukluklarda sik görülen nedenler arasındadır. Ayrıca genç yaş, kronik alkol kullanımı, obesite, stres, sigara kullanımı, gastroözefageal reflü de gögüs ağrısının nedenlerindendir (1). Bu şikâyet geçici olmasına karşın iş göremezlik haline, kalp rahatsızlığı ile ilgili sürekli endişeye ve sağlık hizmetlerinin tekrarlayan kullanımına neden olması açısından önemli bir sağlık sorunudur (2).

Göğüs ağrısı şikâyeti ile kardiyoloji kliniğine başvuran bireylerin yaklaşık olarak yarısına Nonkardiyak göğüs ağrısı (NKGA) tanısı konulmaktadır (3). Toplumdaki bireylerin yaklaşık \%23-33'ü her yıl kalple ilişkili olmayan göğüs ağrısı şikâyeti bildirmektedir (4). Göğüs ağrısı şikâyeti olan ve NKGA tanısı konulan 167 hastadan \%41,3'unde panik bozukluğu, \%9'unda sosyal fobi, \%6'sında yaygın anksiyete bozukluğu, \%6.6'sında özgül fobi, \%7.2'sinde majör depresif bozukluk, $\% 18,6$ 'sında somatizasyon bozukluğu, \%2,4'ünde alkol kullanımı, \%3'ünde hipokondriazis tanılarının bulunduğu gösterilmiştir (5).

Distressed personality'e D Tipi kişilik denilmekte olup bu bireylerde negatif affektivite (NA) ve sosyal inhibisyon (SI) düzeyleri yüksektir (6). SI duygu ve davranışların dışa vurulmasını engelleme eğilimi olup NA ise anksiyete, depresif duygulanım, bireylerle düşmanlık yaşamaya eğilim olarak tanımlanır (6). Bu kişilik yapısına sahip bireyler negatif duyguları yoğun yaşamakla birlikte çevresinden uzaklaşarak yalnız yaşamaya eğilimlidirler.

Aleksitimi, duyguları tanıma ve dışa vurmada zorluk, hayal dünyasında kısıtlılık, duyguların ve içsel arzuların değil dış dünya ile uyumun ve çevresel faktörlerin önemsendiği somut düşünme eğilimi şeklinde kişilik özelliklerini kapsamaktadır (7). Bu kişiler duygularını saptamada ve tanımlamada daha fazla zorluk çeker, bu durum da sağlık anksiyetelerini arttırmaktadır (8). Duygusal deneyimleri daha az veya hafif bildirirlerken fiziksel yakınmalarını daha ciddi dile getirirler. Duyguları tanımada ve ifade etmede yetersizlik olarak tanımlanan aleksitimi kişinin yakınmasını göğüs ağrısı olarak nitelendirmesine neden olabilir (8).

Bedensel duyumları abartma kavramı somatizasyon ile ilişkilendirilir ve bedensel duyumları şiddetli, tehlikeli ve rahatsız edici olarak algılamaya meyil olarak tanımlanır (9). Bu kişiler patolojik olmayan duyumları abartılı olarak hissedebildiği gibi, önemli medikal hastalıklara ait şikâyetleri de abartabilirler.

NKGA hastalarında çocukluk çağı travmaları, depresif belirtiler, bedensel duyumları abartma ve aleksitimi araştırılmış olmakla birlikte D Tipi kişilik örüntüsü ile ilgili literatürde çalışma bulunmamaktadır. Bu nedenle göğüs ağrısı şikâyeti olan bireylerde psikiyatrik belirtiler ile bu belirtilerle hissedilen ağrı şiddeti arasındaki ilişkiyi incelemek için bu çalışma planlanmıştır. Çalışma sonucunda bu bireylerde psikiyatrik faktörlerin farkındalığının arttırılmasını, psikiyatrist tarafından tedavi edilmeleri ile birlikte tekrarlayan hastane başvurularının azaltılabileceğini düşünüyoruz.

\section{GEREÇ VE YÖNTEMLER}

Çalışmamız vaka-kontrol tipindedir. Kafkas Üniversitesi Tıp Fakültesi Etik Kurulundan 27.04.2017 tarih ve 05 numaralı oturumda onay alındıktan sonra çalışmaya başlanılmıştır. Kardiyoloji polikliniğine 01/06/201801/06/2019 tarihleri arasında göğüs ağrısı şikâyeti ile gelen, ağrının niteliği, EKG, toraks radyogramı, akciğerkalp oskültasyonu, troponin-miyoglobin, CK, CK-MB parametrelerinin değerlendirilmesi sonucunda NKGA tanısı konulan 100 kişi ile hasta grubu oluşturulmuştur. Kontrol grubuna göğüs ağrısı şikâyeti olmayan sağlıklı 100 kişi alınmıştır. Helsinki Deklarasyonu Prensipleri'ne uygun olarak çalışma yapılmış olup çalışmaya katılan kişilerden "Bilgilendirilmiş olur" onayı alınmıştır.

\section{Araştırmanın dâhil edilme ölçütleri}

Hasta grubundaki kişilere kardiyolog tarafından NKGA teşhisi konulması, 18-65 yaş arasında olmak ve araştırmaya katılmayı onaylamaktır. Kontrol grubu için ise 18-65 yaş arası olmak, kronik hastalığın olmaması ve araştırmaya katılmayı onaylamaktır.

\section{Araştırmanın dışlama ölçütleri}

Tüm alınan kişiler için araştırmaya katılmayı onaylamamak, zekâ geriliği ve demans tanılarının olmasıdır.

\section{Çalışmada Kullanılan Değerlendirme Gereçleri}

Araştırmaya alınan tüm kişilere Sosyodemografik veri formu, Beck depresyon ölçeği, Çocukluk çağı travmaları ölçeği, D tipi kişilik ölçeği, Bedensel duyumları abartma ölçeği, Toronto aleksitimi ölçeği, Görsel ağrı skalası uygulanmıştır.

Sosyodemografik Veri Formu: $\mathrm{Bu}$ form cinsiyet, medeni hal, öğrenim durumu, yaşı, çalışma durumu sorularından oluşmaktadır.

Beck Depresyon Ölçeği (BDÖ): Depresyonda görülen bilişsel, emosyonel, fiziksel, motivasyonel belirtileri değerlendirmek için geliştirilen bir ölçektir (10). BDÖ'nin Türkçe geçerlilik ve güvenilirlik çalışmalarını Hisli yapmıştır (11).

Çocukluk Çağı Travmaları Ölçeği (ÇÇTÖ): 28 sorudan oluşan bu ölçeğin 5 alt (duygusal-fiziksel ihmal, fiziksel-cinsel-duygusal istismar) ölçeği vardır (12). Şar ve ark. ölçeğin Türkçe geçerlik ve güvenirlik çalışmasını yapmışlardır (13).

D Tipi Kişilik Ölçeği ( Type D Personality Scale, DS14): Bu ölçeğin D Tipi Kişilik örüntüsü değerlendirmekle birlikte 2 alt (negatif affektivite (NA), sosyal inhibisyon (SI) ) ölçeği vardır (14). Sorular Likert tipinde olup 0-4 arasında puanlanırlar. Alt ölçeklerin kesme noktası $\geq 10$ ' dur (15).

Bedensel Duyumları Abartma Ölçeği (BDAÖ): Barsky ve ark. tarafından geliştirilen bu ölçeğin Türkçe geçerlilik ve güvenilirliğini Güleç ve ark. göstermişlerdir $(16,17)$.

Toronto Aleksitimi Ölçeği (TAÖ): Bu ölçek 26 sorudan oluşmakta olup likert tipindedir (18). Dereboy ve ark. ölçeğin Türkçe geçerlik ve güvenirliliğini göstermişlerdir 
(19). Ölçekten alınan puanların artması aleksitiminin de arttığı anlamına gelmektedir.

Görsel Analog Skala (GAS): Ağrı şiddetini ölçmede ve takibinde kullanılır. Bir ucunda ağrısızlık diğer ucunda olabilecek en şiddetli ağrı yazan $10 \mathrm{~cm}$ 'lik bir cetveldir (20).

\section{İstatistiksel Analiz}

İstatistiksel analizler SPSS (Statistical Package for Social Sciences) for Windows 16.0 programı ile yapılmıştır. Araştırmanın verilerinin parametrelerin normal dağılıma uygunluğu için Kolmogorov-Smirnov testi kullanılmıştır. Araştırma sonuçlarında tanımlayıcı istatistikler ortalama, standart sapma, sayı ve yüzde ile niceliksel değişkenlerde normal dağılım gösterenler için iki grup arası karşılaştırmalarında Student t test, niteliksel değişkenleri karşılaştırılırken Ki-kare testi kullanılmıştır. Normal dağılım göstermeyen GAS ölçek puanı ile diğer ölçek puanları arasındaki ilişkinin incelenmesi için Speraman's Korelasyon katsayısı kullanılmıştır. D tipi kişiliğe dayalı olarak görsel ağrı skalasını tahmin etmek için basit lineer regresyon modeli oluşturuldu. Sonuçlar \%95'lik güven aralığında, anlamlılık $\mathrm{p}<0,05$ olarak değerlendirilmiştir.

\section{BULGULAR}

Çalışmada 100'ü kontrol ve 100'ü hasta olmak üzere 200 kişinin verileri değerlendirilmiştir. Hasta grubundakilerin yaş aralığı 22-75 arasında değişmekte iken kontrol grubundakilerin yaş aralığı 23-70 arasında değişmektedir. Hasta grubunun yaş ortalamasını $46,94 \pm 12,79$, kontrol grubunun yaş ortalaması 46,44 $\pm 12,47$ 'dir. Hasta grubundakilerin \%42'si kadın, \%58'i erkek iken kontrol grubundakilerin \%43'ü kadın, \%57'si erkektir (Tablo 1).

\begin{tabular}{|c|c|c|c|c|}
\hline \multicolumn{2}{|c|}{} & $\begin{array}{c}\text { Hasta } \\
(\mathrm{n}=50) \\
\mathrm{N}\end{array}$ & $\begin{array}{c}\text { Kontrol } \\
(\mathrm{n}=50)\end{array}$ & $\mathrm{p}$ \\
& & $\begin{array}{c}\mathrm{N} \\
\%\end{array}$ & \\
\hline \multicolumn{2}{|c|}{ Yaş, Ort. \pm SS } & 46,94 & $46,44 \pm 12,47$ & 0,957 \\
& & $\pm 12,79$ & & \\
\hline Cinsiyet & Kadın & 42 & 43 & 0,886 \\
& Erkek & 42 & 43 & \\
& & 58 & 57 & \\
& & 58 & 57 & \\
\hline Çalışma & Evet & 67 & 57 & 0,145 \\
Durumu & Hayır & 67 & 57 & \\
& & 33 & 43 & \\
& & 33 & 43 & \\
\hline Eğitim & İlkokul & 27 & 19 & 0,373 \\
Durumu & Ortaokul & 27 & 19 & \\
& Lise & 29 & 32 & \\
& Üniversite & 29 & 32 & \\
& & 19 & 27 & \\
& & 19 & 27 & \\
& & 25 & 22 & \\
& & 25 & 22 & \\
\hline
\end{tabular}

Tablo 1. Grupların Sosyodemografik Özellikleri p<0,05; SS: Standart sapma; Ort: Ortalama

Sosyodemografik verilere bakıldığında hasta grubu ile kontrol grubu arasında yaş, cinsiyet, medeni hal, çalışma durumu ve eğitim düzeyleri bakımından anlamlı fark bulunmadı (Tablo 1). Gruplar karşılaştırıldığında BDAÖ, TAÖ, DS-14, BDÖ ve ÇÇTÖ puanları açısından anlamlı fark bulundu (tüm p değerleri <0,001) (Tablo 2).
Tablo 2. Katılımciların Beck Depresyon, Bedensel Duyumları Abartma Ölçeği ve D Tipi Kişilik Ölçeği, Çocukluk Çağı Travmaları Ölçeği, Aleksitimi Ölçek Puanlarının Değerlendirilmesi

\begin{tabular}{|l|c|c|c|c|}
\hline & $\begin{array}{c}\text { Hasta } \\
\text { Ort. } \pm \text { SS }\end{array}$ & $\begin{array}{c}\text { Kontrol } \\
\text { Ort. } \pm \mathrm{SS}\end{array}$ & $\mathrm{t}$ & $\mathrm{p}$ \\
\hline BDÖ & $11,57 \pm 3,38$ & $8,05 \pm 4,03$ & 6,69 & $<0,001$ \\
\hline TAÖ & $61,64 \pm 7,68$ & $41,96 \pm 6,67$ & 19,352 & $<\mathbf{0 , 0 0 1}$ \\
\hline DS-14 & $24,20 \pm 11,78$ & $18,06 \pm 9,09$ & 4,127 & $<\mathbf{0 , 0 0 1}$ \\
\hline ÇÇTÖ & $65,64 \pm 18,47$ & $53,99 \pm 17,08$ & 4,631 & $<\mathbf{0 , 0 0 1}$ \\
\hline BDAÖ & $23,10 \pm 4,35$ & $19,86 \pm 6,40$ & 4,185 & $<\mathbf{0 , 0 0 1}$ \\
\hline
\end{tabular}

BDÖ; Beck Depresyon Ölçeği, TAÖ; Toronto Aleksitimi Ölçeği, DS-14; DS-14 ölçeği, ÇÇTÖ; Çocukluk çağı travmaları ölçeği, BDAÖ; Bedensel duyumları abartma ölçeği. p<0,05; SS: Standart Sapma; Ort: Ortalama t: student t testi

Hasta grubundakilerin GAS ile BDÖ, BDAÖ ve DS-14, ÇÇTÖ, TAÖ toplam puanı arasındaki ilişkinin incelenmesinde kullanılan Spearman rho Korelasyon testi analiz sonuçlarına göre GAS ile BDAÖ, ÇÇTÖ, BDÖ, TAÖ ölçeği puanları arasında istatistiksel olarak anlamlı bir ilişki yoktur $(p>0,05)$. GAS ile D tipi kişilik özellikleri ölçeği puanları arasında pozitif yönde zayıf bir ilişki vardır $(p<0,01 r=0,273)$. Bir başka ifadeyle GAS puanı artarken D tipi kişilik özellikleri de artmaktadır (Tablo 3).

Tablo 3. Hasta Grubunda Görsel Analog Skalası ile Beck Depresyon, Bedensel Duyumları Abartma Ölçeği, D Tipi Kişilik, Çocukluk Travması ve Aleksitimi ölçek puanları arasındaki ilişki

\begin{tabular}{|l|c|c|}
\hline \multirow{2}{*}{ Hasta } & \multicolumn{2}{|c|}{ Görsel Analog Skala } \\
\cline { 2 - 3 } & $\mathrm{r}$ & $\mathrm{p}$ \\
\hline BDAÖ & 0,138 & 0,17 \\
\hline ÇÇTÖ & 0,007 & 0,944 \\
\hline BDÖ & $-0,022$ & 0,829 \\
\hline Ds-14 & 0,273 & 0,006 \\
\hline TAÖ & 0,054 & 0,593 \\
\hline
\end{tabular}

BDÖ; Beck Depresyon Ölçeği, TAÖ; Toronto Aleksitimi Ölçeği, DS-14; DS-14 ölçeği, ÇÇTÖ; Çocukluk çağı travmaları ölçeği, BDAÖ; Bedensel duyumları abartma ölçeği. p $<0,05$; r: korelasyon katsayıs1

D tipi kişiliğe dayalı olarak görsel ağrı skalasını tahmin etmek için basit lineer regresyon modeli oluşturuldu. Hesaplanan regresyon modeli istatistiksel olarak anlaml bulundu $[F(1,98)=11,582, p=0,001]$ ve $R^{2}=0,106$ olarak elde edildi. Katılımcıların tahmini görsel ağrı skalası değeri, D tipi kişilik ölçek puanı cinsinden ölçüldüğünde 4,751+0,022 (D Tipi kişilik)'a eşittir. Katılımcıların görsel ağrı skalası değeri, d tipi kişilik puanının her bir birimi için 0,022 artış göstermektedir (Tablo 4). 
Tablo 4. Regresyon Analizi Sonuçları

\begin{tabular}{|l|l|l|l|l|l|}
\hline & $\beta^{1}(\% 95 \mathrm{CI})$ & SE & $\beta^{2}$ & $\mathrm{t}$ & $\mathrm{p}$ \\
\hline Constant & $4,751(4,408-5,094)$ & 0,173 & & 27,494 & $<0,001$ \\
\hline D Tipi Kişilik & $0,022(0,009-0,035)$ & 0,006 & 0,325 & 3,403 & 0,001 \\
\hline
\end{tabular}

$\mathrm{F}(1,98)=11,582 ; \mathrm{p}=0,001 ; \mathrm{R}^{2}=0,106 ;$ SE of Estimate $=0,753 ;{ }^{1}:$ Standartlaştırılmamış Katsay1; ${ }^{2}$ : Standartlaştırılmış Katsayı; Durbin-

Watson $=2,393$

\section{TARTISSMA}

Bu çalışmada nonkardiyak göğüs ağrısına sahip hastalar; sosyodemografik özellikler, depresif belirtiler, aleksitimi, bedensel duyumları abartma, D Tipi kişilik örüntüsü ve çocukluk çağı travmatik yaşantılar açısından kontrol grubu ile karşılaştırılmıştır. Çalışmamızın sonuçlarına göre hasta gurubunda kontrol grubuna göre depresyon, aleksitimi, bedensel duyumları abartma, D Tipi kişilik ve çocukluk çağı travmatik yaşantılar ölçek puanları anlamlı olarak daha yüksektir. Ayrıca D Tipi kişiliğe sahip olmanın ağrı şiddetini arttırdığı bulunmuştur.

Çalışmamızın sonuçlarına göre, yaş, cinsiyet, eğitim, çalışma durumu açısından hasta ve kontrol grubunda anlamlı fark tespit edilmemiştir. Literatür ile çalışmamızın sonuçları uyumludur.

Yapılan birçok çalışma da NKGA tanılı hastalarda depresif belirtilerin daha sik oranda görüldüğü bildirilmiştir (21). Çalışmamızda da hasta grubunda BDÖ puanları kontrol grubuna göre istatistiksel olarak anlamlı derecede yüksektir. Depresif dönemdeki kişilerde sık görülen negatif düşüncelerin gelecek ve sağlıklarını olumsuz değerlendirdiklerini ve sonuç olarak basit ve hafif belirtileri bile daha şiddetli olarak hissettikleri düşünülmektedir.

D Tipi kişilik örüntüsünde sosyal inhibisyon ve negatif affektivite görülür. Bireylerde görülen sık sık tekrarlayan göğüs ağrısı şikâyetleri ağrıya bağlı korkuya neden olabilir (22). Bu kişiler ağrının nedeni olarak gördüğü fiziksel aktiviteden kaçınır ve hayatlarını bu duruma göre düzenlerler. Çalışmamızda da hasta grubunda D Tipi kişilik ölçeği puanları kontrol grubuna göre istatistiksel olarak anlamlı derecede yüksektir. Ayrıca bedensel duyumları abartma somatik duyarlılıktan çok olumsuz duygulanım ile ilişkilidir (23). Olumsuz duygulanım D Tipi kişilik örüntüsünün de özelliğidir. NKGA şikâyetine sahip hastaların bu şikâyet ortaya çıkmadan önce D Tipi Kişilik örüntüsüne sahip olup olmadıkları konusunda fikir sahibi olunamamıştır.

NKGA hastaları ile sağlıklı kontrollerin karşılaştırıldığ çalışmada bedensel duyumları büyütme ölçeği ile değerlendirilen somatosensoriyel duyarlılık NKGA hastalarında anlamlı olarak yüksek çıkmıştır (8). Çalışmamızda da hasta grubunda bedensel duyumları abartma ölçeği puanları kontrol grubuna göre istatistiksel olarak anlamlı derecede yüksektir. Danimarka'da, 75 göçmen Türk kadını ile yapılan bir çalışma da, göçmen kadınlarda somatizasyona bir yatkınlı olduğu bildirilmiştir. En sık görülen belirti gögüste ağrı-sıkışma olmakla birlikte kas ağrısı, baş ağrısı, nefes darlığı da görülmektedir (24). Kişilerin somatik şikâyetler vasıtasıyla tıbbi yardım arayışlarının nedeni olarak emosyonel rahatsızlık ya da kişilerarası ilişkilerdeki sorunların dışarı yansıtılması olduğu düşünülmektedir.
Psikanalitik görüşe göre aleksitimik bireyler çevresine yansıtamadığı duygularını fiziksel şikâyet olarak göstermektedir. Bu durumun nedeni olarak da gelişmemiş savunma mekanizmaları veya yaşanılan travmatik yaşantıların olduğu düşünülmektedir (25). Depresyon tanısı olan aleksitimik bireylerde bedensel duyumları abartma eğiliminin yüksek olduğu literatürde bildirilmiştir (26). Çalışmamızda da literatürle uyumlu olarak hasta grubundaki olgularda aleksitimi ile birlikte depresif belirtilerin daha yüksek oranda olduğu tespit edilmiştir.

Travmatik yaşantıların sonuçları kısa sürede görülebileceği gibi uzun süreç sonunda da ortaya çıkabilmektedir. $\mathrm{Bu}$ yaşantılara sahip çocukların biyopsikososyal bütünlük ve gelişimde sorunlar görülmektedir (27). Bu travmatik yaşantıların erişkin dönemdeki somatik belirtiler ile ilişkili olabileceği bildirilmiştir. Erişkinlerde görülen tekrarlayan vücut ağrıları gibi organik nedeni tespit edilemeyen şikâyetlerin erken yaşam yıllarındaki olumsuz yaşantıları ile ilişkili olduğu bilinmektedir (27). Çalışmamızda da hasta grubunda ÇÇTÖ'inden alınan puanların kontrol grubuna göre istatistiksel olarak anlamlı derecede yüksektir.

Çalışmamızın kısıtlılıkları arasında tek merkezde yapılmış olması, hasta sayısının az olması söylenilebilir. Bununla beraber bu kısıtlılık çok önemli olmayabilir; çünkü $\alpha=0,05$ etki büyüklüğü 0,8 olması için olgu ve kontrol gruplarının 64 kişiden oluşması yeterli iken, çalışmamızda hem olgu hem de kontrol grubunda 100 kişi bulunmaktadır. Ayrıca kesitsel bir çalışma olması da diğer bir kısıtlılıktır. Çok sayıda kişi ile çok merkezli yapılacak çalışmalar ile sonuçlarının toplumu tam olarak yansitması beklenebilir.

\section{SONUÇ}

Çalışmamızda NKGA şikâyeti olan hastalarda kontrol grubuna göre depresyon, aleksitimi, bedensel duyumları abartma, D Tipi Kişilik ve çocukluk çağı travmatik yaşantılar ölçek puanlarının anlamlı olarak daha yüksek olduğu ayrıca D Tipi kişilik özelliklerinin ağrı şiddeti ile ilişkili olduğu bulunmuştur. NKGA şikâyeti olan kişiler sağlık kuruluşlarına aynı nedenle kısa sürelerde çok sayıda başvuru öyküsü olan ve gereksiz yere kardiyolojik tanı konulabilmesi için çok sayıda test yapılan hasta grubunu oluşturur. $\mathrm{Bu}$ durum da sağlık hizmeti sunucularında yoğunluğa ve gereksiz ekonomik maliyetlere yol açmaktadır. Ayrıca insanlarda bu şikâyete yönelik artmış zihinsel uğraşlar sonucunda yaşam kalitesi ve işlevsellikte azalmalar görülmektedir. Bu şikâyetin etiyolojisinde psikiyatrik faktörlere yönelik psikiyatri dişı hekimlerde farkındalığın arttırılması ile bu hastaların daha erken zamanlarda psikiyatrik tedavi-takibe 
başlanılması ile yaşanılabilecek bireysel ve toplumsal olumsuzluklar önlenebilir.

\section{Çıkar Çatışması}

Yazarların bu makale ile ilgili olarak herhangi bir çıkar çatışması bulunmamaktadır.

\section{Mali Destek}

Çalışmamız için hiçbir kurum ya da kişiden finansal destek alınmamıştır.

Yazar Katkıları: Fikir/Kavram İ.Y, Y.T., F.A. Tasarım İ.Y. Veri Toplama ve/veya İşleme F.A.,Y.T. Analiz ve/veya Yorum I.Y. Literatür Taraması İ.Y., Y.T., F.A., Makale Yazımı İ.Y., F.A., Y.T. Eleştirel İnceleme İ.Y., Y.T., F.A.

\section{KAYNAKLAR}

1. Eslick GD. Usefulness of chest pain character and location as diagnostic indicators of an acute coronary syndrome. Am J Cardiol. 2005; 95(10): 15-8.

2. Mayou RA, Bryant B, Forfar C. Non-cardiac chest pain and bening palpitations in the cardiac clinic. $\mathrm{Br}$ Heart J. 1994; 72(6): 548-53.

3. Bokma WA, Batelaan NM, Beek AM, Boenink AD, Smit JH, Balkom AJ. Feasibility and outcome of the implementation of a screening program for panic disorder in noncardiac chest pain patients in cardiac emergency department routine care. Gen Hosp Psychiatry. 2015; 37(5): 485-7.

4. Eslick GD, Talley NJ. Natural history and predictors of outcome for non-cardiac chest pain: A prospective 4-year cohort study. Neurogastroenterol Motil. 2008; 20(9): 989-97.

5. Dammen T, Arnesen H, Ekeberg O. Psychological factors, pain attribution and medical morbidity in chest-pain patients with and without coronary artery disease. Gen Hosp Psychiatry. 2004; 26(6): 463-9.

6. Pederson S, Denollet J. Type D Personality, cardiac events, and impaired quality of life: a review. Eur $\mathbf{J}$ Cardiovasc Prev Rehabil. 2003; 10(4): 241-8.

7. Sifneos PE, Apfel-Savitz R, Frankel FH. The Phenomenon of 'Alexithymia.' Psychother Psychosom. 1977; 28(1-4): 47-57.

8. Zincir, SB, Sunbul M, Sunbul EA, Dalkilic B, Cengiz F, Kivrak T, et al. Evaluation of Alexithymia, Somatosensory Sensitivity, and Health Anxiety Levels in Patients with Noncardiac Chest Pain. Biomed Res Int. 2014; 89: 61-83.

9. Barsky AJ. Amplification, somatization, and the somatoform disorders. Psychosomatics. 1992; 33(1): 28-34.

10. Beck AT. An inventory for measuring depression. Arch Gen Psychiatry. 1961; 4(6): 561-71.

11. Hisli N. Beck Depresyon Envanterinin geçerliliği üzerine bir çalışma. Psikoloji Dergisi. 1988; 6: 11822.

12. Bernstein DP, Fink L, Handelsman L, J Foote, M Lovejoy, $\mathrm{K}$ Wenzel, et al. Initial reliability and validity of a new Retropective measure of child abuse and neglect. Am J Psychiatry. 1994; 151(8): 1132-6.

13. Şar V, Öztürk E, İkikardeş E. Çocukluk Çağı Ruhsal Travma Ölçeğinin (CTQ) Türkçe uyarlamasının geçerlik ve güvenilirliği. Türkiye Klinikleri Tıp Bilimleri Dergisi. 2012; 32(4): 1054-63.
14. Denollet J. DS14: Standard assessment of negative affectivity, social inhibition, and Type D personality. Psychosom Med. 2015; 67(1): 89-97.

15. Alçelik A, Yıldırım O, Canan F, Eroğlu M, Aktaş G, Savli H. A preliminary psychometric evaluation of the type D personality construct in Turkish hemodialysis patients. Journal of Mood Disorders. 2012; 2(1): 1-5.

16. Barsky AJ, Goodson JD, Lane RS The amplification of somatic symptoms. Psychosom Med. 1988; 50(5): 510-9.

17. Güleç H, Sayar K. The Reliability and validity of the Turkish form of the somatosensory amplification scale. Psychiatry Clin Neurosci. 2007; 61(1): 23-8.

18. Taylor GJ, Ryan D, Bagby RM. Toward the development of a new self-report alexithymia scale. Psychother Psychosom. 1985; 44(4): 191-9.

19. Dereboy İF. Aleksitimi: Bir Gözden Geçirme. Türk Psikiyatri Derg. 1991; 1(3): 157-65.

20. Price DD, McGrath PA, Rafii A, Buckingham B. The validation of visual analogue scales as ratio scale measures for chronic and experimental pain. Pain 1983; 17(1): 45-56.

21. Webster R, Norman P, Goodacre S, Thompson A. The prevalence and correlates of psychological outcomes in patients with acute non-cardiac chest pain: A systematic review. Emerg Med J. 2012; 29(4): 267-73.

22. Leeuw M, Goossens MEJB, Linton SJ, Crombez G, Boersma K, Vlaeyen JWS. The fear-avoidance model of musculoskeletal pain: Current state of scientific evidence. J Behav Med. 2007; 30(1): 77-94.

23. Kellner R, Hernandez J, Pathak D. Hypochondriacal fears and beliefs, anxiety, and somatisation. $\mathrm{Br} J$ Psychiatry. 1992; 160(4): 86.

24. GM M. The condition of "tightness": the somatic complaints of Turkish migrant women. Acta Psychiatr Scand. 1985; 71(3): 287-96.

25. De Tychey C, Garnier S, Lighezzolo-Alnot J, Claudon P, Rebourg-Roesler C. An accumulation of negative life events and the construction of alexithymia: A longitudinal and clinical approach. J Pers Assess. 2010; 92(3): 189-206.

26. Taycan O, Özdemİr A, Taycan SE. Depresyon Hastalarında Aleksitimi ve Bedenselleştirme Belirtileri Bedensel Nedenlere Bağlama Biçiminin Rolü. Nöropsikiyatri Arşivi. 2017; 54(2): 99.

27. Hotopf M, Mayou R, Wadsworth M, Wessely S. Childhood risk factors for adults with medically unexplained symptoms: results from a national birth cohort study. Am J Psychiatry. 1999; 156(11): 1796800 . 